\title{
Stratification of Breast Cancer Risk in Terms of the Influence of Age and Mammographic density
}

\section{Stratifizierung des Brustkrebsrisikos hinsichtlich der Einflüsse von Alter und mammografischer Dichte}

Authors

Stefanie Weigel ${ }^{1}$, Walter Heindel' ${ }^{1}$, Caroline Dietz ${ }^{2}$, Ulrike Meyer-Johann ${ }^{3}$, Axel Graewingholt ${ }^{4}$, Hans Werner Hense ${ }^{5}$

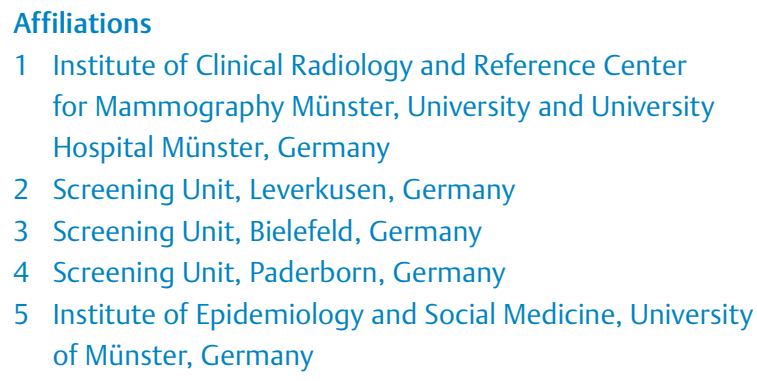

1 Institute of Clinical Radiology and Reference Center for Mammography Münster, University and University Hospital Münster, Germany

2 Screening Unit, Leverkusen, Germany

3 Screening Unit, Bielefeld, Germany

4 Screening Unit, Paderborn, Germany

5 Institute of Epidemiology and Social Medicine, University of Münster, Germany

Key words

breast cancer screening, digital mammography, breast density, age, interval cancer, population surveillance

received 10.03.2019

accepted 22.12.2019

Bibliography

DOI https://doi.org/10.1055/a-1100-0016

Published online: 27.2.2020

Fortschr Röntgenstr 2020; 192: 678-685

(c) Georg Thieme Verlag KG, Stuttgart · New York

ISSN 1438-9029

Correspondence

Prof. Stefanie Weigel

Institute of Clinical Radiology, University and University

Hospital Münster, Albert-Schweitzer-Campus 1,

48149 Münster, Germany

Tel.: ++49/2 51/8345650

Fax: ++49/2 51/8345660

weigels@uni-muenster.de

\section{ABSTRACT}

Purpose Analysis of the influence of the singular risk factors age and breast density on the 2-year incidence of breast cancer among participants in the German mammography screening program.

Materials and Methods The multicenter study includes 111456 subsequent round digital mammographic screening examinations from four screening units with prospective visual categorization of breast density. Based on detection in screening and during the 2-year interval after negative screening participation (interval cancers), 2-year breast can- cer incidences (2 YBCI) (\%) were calculated in the 5-year age groups (5 YAG) of the target group 50-69 years and in the BI-RADS density categories ACR 1-4. Multivariate statistical evaluations were carried out using logistic regression models. Results With an increase in the 5 YAG, the $2 \mathrm{YBCl}$ increased by $5.0 \%, 6.7 \%$, $8.5 \%$ o to $9.7 \%$, and was significantly different among 55-59, 60-64 and 65-69-year-old women compared to the youngest reference group $50-54$ years (odds ratio (OR): 1.34 ; 1.68 ; and 1.93 ; p-value $<0.0001$ ). With an increase in density categories $1-4$, the $2 \mathrm{YBCl}$ increased from $2.6 \%$, to $5.8 \%$, $9.6 \%$, and $9.7 \%$. The $2 \mathrm{YBCl}$ differed significantly in breast density categories 2, 3, 4 from reference group 1 (OR: 2.17; 3.65; and 3.76; p-value <0.0001). Only within the two main breast density groups 2 (frequency $44.3 \%$ ) and $3(44.7 \%)$, a significant increase in the $2 \mathrm{YBCl}$ was observed across the 5 YAG (category 2: 3.7-8.9\%; category 3: 5.8-11.7\%; p-value $<0.001$ each). The $2 \mathrm{YBCl}$ was above the median of $7.5 \%$ in women with breast density category 2 and aged 65-69 years, as well as in women with breast density categories 3 and 4 aged 55-69 years. A 2 YBCI below the median was seen in women between $50-54$ years regardless of breast density, as well as women in category 1 in all age groups.

Conclusion Within the main breast density categories 2 and 3 (almost $90 \%$ of participants), incidences increase with age to double. A consistently low incidence is found regardless of breast density at a young screening age and in women with the lowest breast density.

\section{Key Points:}

- The risk of breast cancer is modified by age in density categories.

- Women aged 50-54 years have a low risk in all density categories.

- Women in category ACR 1 of any age group have a low risk.

\section{Citation Format}

- Weigel S, Heindel W, Dietz C et al. Stratifizierung des Brustkrebsrisikos hinsichtlich der Einflüsse von Alter und mammografischer Dichte. Fortschr Röntgenstr 2020; 192: 678-685 


\section{ZUSAMMENFASSUNG}

Ziel Analyse des Einflusses der singulären Risikofaktoren Lebensalter und Brustdichte auf die 2-Jahres-Inzidenz des Mammakarzinoms unter Teilnehmerinnen am deutschen Mammografie-Screening-Programm.

Material und Methode Die multizentrische Studie umfasst 111456 digitale mammografische Folgerunden-Untersuchungen aus 4 Screening-Einheiten mit prospektiver visueller Kategorisierung der Brustdichte. Basierend auf der Detektion im Screening und im 2-jahres-Intervall nach negativer Screening-Teilnahme (Intervallkarzinome) wurden 2-Jahres-Brustkrebsinzidenzen (2-JBI) (\%) in den 5-Jahres-Altersgruppen (5-JAG) der Zielgruppe 50-69 Jahre und in den Dichtekategorien ACR 1-4 berechnet. Multivariate statistische Auswertungen erfolgten mit logistischen Regressionsmodellen.

Ergebnisse Mit steigender 5-JAG stieg die 2-JBI von 5,0\%, $6,7 \%$ und $8,5 \%$ auf $9,7 \%$ und unterschied sich unter den 55-59-, 60-64- und 65-69-jährigen Frauen signifikant von der jüngsten Referenzgruppe 50-54 Jahre (Odds-Ratio (OR):
1,34, 1,68 bzw. 1,93; p<0,0001). Mit Anstieg der ACR-Kategorien 1-4 nahm die 2 JBI von 2,6\%, auf 5,8\%, 9,6\% und $9,7 \%$ zu. Die 2-JBI unterschied sich in ACR 2, 3 und 4 signifikant von der Referenzgruppe ACR 1 (OR: 2,17, 3,65 bzw. 3,76; $\mathrm{p}<0,0001)$. Nur innerhalb der beiden Hauptgruppen ACR 2 (Häufigkeit 44,3\%) und ACR 3 (44,7\%) zeigte sich ein signifikanter Anstieg der 2-JBI über die 5-JAG (ACR 2: 3,7\%o-8,9\%; ACR 3: $5,8 \%-11,7 \%$; $p<0,001)$. 2-JBI lagen über dem Median von 7,5\% bei Frauen mit ACR 2 und Alter 65-69 Jahre sowie bei ACR 3 und ACR 4 im Alter 55-69 Jahre. 2-JBI unter dem Median hatten Frauen zwischen 50-54 Jahren, unabhängig von der Brustdichte, sowie Frauen der Kategorie ACR 1 in allen Altersgruppen.

Schlussfolgerung Innerhalb der Hauptkategorien ACR 2 und ACR 3 (fast $90 \%$ der Teilnehmerinnen) steigen die Inzidenzen mit zunehmendem Alter bis zu einer Verdopplung. Eine konsistent niedrige Inzidenz findet sich unabhängig von der Brustdichte bei jungem Screening-Alter und bei Frauen mit geringster Brustdichte.

\section{Introduction}

Breast cancer is the most common fatal cancer among women [1]. Population-based mammography screening programs have been implemented to allow earlier diagnosis of breast cancer by means of systematic imaging and to help to reduce the mortality rate as a result of earlier initiation of treatment [2]. There is an estimated reduction in breast cancer mortality of $20-40 \%$ for women between 50 and 69 years of age participating in mammography screening [3].

Established risk factors for breast cancer include age, precancerous precursor lesions, genetic predisposition, positive personal and family history, hormone therapies, ionizing radiation, alcohol consumption, and postmenopausal obesity [3]. While structured intensified surveillance for early detection is performed in the case of a genetic predisposition for breast cancer [4], the justification for early detection examinations as part of population-based mammography screening programs is based on the risk factor "age". National statistics show that age is a relevant risk factor for breast cancer. Therefore, 1 in 110 women 35 years old will develop breast cancer in the next 10 years. The risk is highest at 65 years of age. 1 in 27 women is affected by the age of 75 [5].

Studies have also shown that higher breast density is also a strong independent biomarker for an increased risk of breast cancer [6-9]. Breast density can be determined from mammography and relates to the ratio of radiopaque epithelium and stroma to radiolucent fatty tissue. In addition, higher breast density has a masking effect on mammography [6, 7].

Scientific approaches focus on the development of risk-adjusted early detection concepts for women also outside of high-risk groups for breast cancer [10]. However, knowledge of the combination of risk constellations is currently still limited. Detection requires consideration of breast cancer diagnoses in the interval between screening examinations. Although this information can be obtained from population-based cancer registries including tumor-specific data, such as staging, grading, etc., data regarding imaging criteria, such as mammographic density values, is not available there.

Therefore, the goal of the present study is to analyze the effect of age and breast density on the incidence of breast cancer in a 2-year period among participants in the German mammography screening program.

\section{Materials and Methods}

\section{Screening procedure and data collection}

The national mammography screening program is based on the European guidelines [2]. The target group is women aged 5069 years. All eligible women in the population are mailed an invitation to participate in two-year intervals.

111456 of 111470 subsequent digital screening examinations that were generated at four screening units between January 2009 and December 2010 and comprised ACR categorization were included in the study. Independent double reading provided the evaluation of abnormal mammography findings [11] as well as independent visual categorization of breast density according to the American College of Radiology Breast Imaging Reporting and Data System Version 4. The percentage of dense tissue increases by $25 \%$ per category: ACR 1 lipomatous, ACR 2 fibroglandular, ACR 3 heterogeneously dense, ACR 4 extremely dense [12]. For study purposes the higher ACR category was used if the independent second reading yielded a different density category for an examination.

All examinations were obtained using the digital technique in two views (cranio-caudal, medio-lateral-oblique) (Lorad Selenia, Hologic; MammoDiagnost, Philips; Mammomat 3000 Nova, Sie- 
mens AG; MicroDose Mammography, Sectra Medical Systems; Senographe DS, GE Healthcare; Senographe Essential, GE Healthcare).

According to the defined screening procedure, a consensus conference including both readers and the physician responsible for the program was held in the case of an abnormal mammography finding by at least one interpreting physician in order to decide whether further diagnostic workup is indicated. Diagnostic workup was performed in accordance with regulations by the physician responsible for the program [11].

Screening was documented by screening software with an interface to the national cancer registry in North Rhine-Westphalia. The national cancer registry receives electronic messages about all cases of breast cancer detected for the first time as part of and outside of mammography screening (incidence report). Breast cancers are recorded as invasive breast cancer (ICD-10 C50) and ductal carcinoma in situ (DCIS; ICD-10 D05). A differentiation is made between cases detected during screening and cases of interval cancer. The interval is defined as the 24-month period following participation in the mammography screening program with a negative examination result. The study included corresponding collection of interval cancer data including December 2012.

\section{Statistical calculations}

Breast cancer incidences were calculated as the sum of the breast cancer cases detected during screening and the cases of interval cancer detected in the 2-year interval after a negative screening result in relation to the total number of screened women.

The breast cancer incidences were calculated in the 5-year age groups and in the density categories ACR 1-4 per 1000 screening participants.

The program sensitivity (PS) was calculated as the number of screening-detected breast cancer cases divided by the sum of screening-detected breast cancer cases plus interval cancers.

Multivariate statistical evaluations were performed with logistic regression models in which the four age groups and the four ACR categories were defined as binary dummy variables. In addition, an adjustment to the four screening units was performed. The results of the regression models are presented as odds ratios with $95 \%$ confidence intervals. Moreover, a p-value for an age or ACR variable with four attribute levels was determined. The software SAS for Windows 9.4 was used for the evaluations.

\section{Results}

\section{Stratification by age}

The total group of 111,456 examinations of all age groups had a 2 -year breast cancer incidence of $7.5 \%$. The percentages of the 5 -year age groups among screening participants ranged from $21 \%$ to $29 \%$.

The 2-year breast cancer incidences were 5.0\%, $6.7 \%$, $8.5 \%$, and $9.7 \%$, respectively for the 5 -year age groups in increasing order. Older participants had a significantly higher 2-year incidence than the reference group of 50-54-year-olds (odds ratio
(OR: 1.34 (55-59 years); 1.68 (60-64 years); 1.93 (65-69 years); p-value <0.0001) ( Table 1).

The group as a whole had a program sensitivity of $77.7 \%$. The values were lower in women under the age of 60 and higher in women 60 or older ( $\vee$ Table 1 ).

\section{Stratification by breast density category}

The means of the visual density categories according to ACR for the first and second reading were $2.32 \pm 0.71$ and $2.31 \pm 0.71$, respectively. A discrepancy resulting in a higher classification between the first and second reading was seen in $16.7 \%(18,622)$ $111,456)$ of the examinations. $30.7 \%$ of these cases with a higher category were category ACR 2, 57.6\% were category ACR 3, and $11.7 \%$ were category ACR 4 .

In the group as a whole, ACR categories 2 and 3 were most common with a percentage of $44 \%$ and $45 \%$, respectively, while ACR 1 and ACR 4 were less common with a percentage of $6 \%$ and $5 \%$, respectively.

The 2-year breast cancer incidences for ACR categories 1 to 4 were $2.6 \%$, $5.8 \%$, $9.6 \%$ and $9.7 \%$, respectively. The breast cancer incidence for ACR 2, 3 and 4 differed significantly from ACR 1 as the reference group $(O R=2.17,3.65$, and 3.76; $p$-value $<0.0001)$ $(\triangleright$ Table 2).

The largest density groups ACR 2 and ACR 3 had program sensitivities of $84.0 \%$ and $74.7 \%$, respectively ( Table 2 ).

\section{Stratification by age group and breast density category}

In the subgroups resulting from the simultaneous stratification by age group and ACR category, the 2-year breast cancer incidence varied from $1.6 \%$ among 55-59 year-olds in category ACR 1 to $13.3 \%$ among 60-64-year-olds in category ACR 4. Increased breast cancer incidences over the total median (>7.5\%) were seen in the case of the following combinations: ACR 2 and the oldest age group, ACR 3 and all age groups except the youngest, ACR 4 and all age groups except the youngest. Lower 2-year incidences for breast cancer were seen in women in the youngest age group (50-54 years) in every ACR category and women in category ACR 1 in every age group ( $\triangleright$ Table 3 ).

In both of the main groups (ACR 2 and ACR 3), a significant increase in the 2-year breast cancer incidence among the 5-year age groups was seen (ACR 2: $3.7 \%$ to $8.9 \%$; ACR 3: $5.8 \%$ to $11.7 \%$; p-value <0.001) ( Fig. 1).

- Fig. 2 shows the discrepancies in the frequency distribution of breast cancers in the 2-year time period depending on breast density and age.

\section{Discussion}

The singular risk factors "age" and "breast density" have a cumulative effect on the breast cancer incidence in the main groups "fibroglandular" and "heterogeneously dense". The increase in incidence between the 5 -year age groups in the two most prevalent ACR groups ranged from $3.7 \%$ to $8.9 \%$ (ACR 2) and from $5.8 \%$ to $11.7 \%$ (ACR 3 ). In addition, the age-specific differences 
- Table 1 Number of women screened in subsequent rounds, number of women with screening (ScD)- and interval (ICD)-detected breast cancers (invasive breast cancers plus ductal carcinoma in situ (DCIS)); per 1000 women screened, by 5 -year age group.

\begin{tabular}{|c|c|c|c|c|c|c|}
\hline & \multirow{2}{*}{$\begin{array}{l}\text { total } \\
50-69 \text { years }\end{array}$} & \multicolumn{4}{|c|}{ 5-year age groups } & \multirow[t]{2}{*}{ p-value ${ }^{1}$} \\
\hline & & $50-54$ years & $55-59$ years & $60-64$ years & $65-69$ years & \\
\hline number screened (\%) & $111456(100.0)$ & 23954 (21.49) & 32201 (28.89) & $26360(23.65)$ & 28941 (25.96) & \\
\hline $\begin{array}{l}\text { number of women with } \\
\text { ScD plus ICD breast cancer, }\end{array}$ & 838 & 120 & 216 & 221 & 281 & \\
\hline ScD; ICD & $651 ; 187$ & $87 ; 33$ & $160 ; 56$ & $178 ; 43$ & 226; 55 & \\
\hline $\begin{array}{l}\text { 2-year breast cancer incidence } \\
\text { (per } 1,000 \text { women screened) }\end{array}$ & 7.5 & 5.0 & 6.7 & 8.5 & 9.7 & \\
\hline $\begin{array}{l}\text { program sensitivity } \\
(\mathrm{ScD} /[\mathrm{ScD}+\mathrm{ICD}])\end{array}$ & $77.7 \%$ & $72.5 \%$ & $74.2 \%$ & $80.7 \%$ & $80.4 \%$ & \\
\hline $\begin{array}{l}\text { adjusted }{ }^{2} \text { odds ratio } \\
\text { (95\% confidence interval) }\end{array}$ & & Ref. & $1.34(1.07-1.68)$ & $1.68(1.34-2.10)$ & $1.93(1.55-2.39)$ & $P<0.0001$ \\
\hline \multicolumn{7}{|c|}{$\begin{array}{l}1 \text { p-value for one age variable with four levels ( } 1=\text { ' } 50-54 \text { ', } 2=\text { = '55-59', } 3=\text { ='60-64', } 4=65-69 \text { ') as obtained from the multivariable logistic regression } \\
\text { model, adjusted for screening unit. }\end{array}$} \\
\hline
\end{tabular}

- Table 2 Number of women screened in subsequent rounds, number of women with screening (ScD)- and interval (ICD)-detected breast cancers (invasive breast cancers plus ductal carcinoma in situ (DCIS)); per 1000 women screened, by ACR categories.

\begin{tabular}{|c|c|c|c|c|c|c|}
\hline & total & ACR 1 & ACR 2 & ACR 3 & ACR 4 & p-value ${ }^{1}$ \\
\hline number screened (\%) & $111456(100.0)$ & $6512(5.84)$ & $49348(44.28)$ & $49819(44.70)$ & $5777(5.18)$ & \\
\hline $\begin{array}{l}\text { number of women with } \\
\text { ScD plus ICD breast cancer, }\end{array}$ & 838 & 17 & 287 & 478 & 56 & \\
\hline ScD; ICD & $651 ; 187$ & $13 ; 4$ & $241 ; 46$ & $357 ; 121$ & $40 ; 11$ & \\
\hline $\begin{array}{l}\text { 2-year breast cancer incidence } \\
\text { (per 1,000 women screened) }\end{array}$ & 7.5 & 2.6 & 5.8 & 9.6 & 9.7 & \\
\hline $\begin{array}{l}\text { program sensitivity } \\
(\mathrm{ScD} /[\mathrm{SCD}+\mathrm{ICD}])\end{array}$ & $77.7 \%$ & $76.5 \%$ & $84.0 \%$ & $74.7 \%$ & $71.4 \%$ & \\
\hline $\begin{array}{l}\text { adjusted }{ }^{2} \text { odds ratio } \\
\text { ( } 95 \% \text { confidence interval) }\end{array}$ & & Ref. & $2.17(1.33-3.55)$ & $3.65(2.25-5.92)$ & $3.76(2.18-6.48)$ & $<0.0001$ \\
\hline
\end{tabular}

between the ACR groups increased with age. The breast cancer incidence in density category ACR 3 among 50-54-year-olds was $2.1 \%$ higher than in ACR 2, $5.3 \%$ o higher among 55-59-yearolds and $6.3 \%$ higher among 60-64-year-olds. However, the difference decreased to $2.8 \%$ among 65-69-year-olds. The highest incidence was $13.3 \%$ for women between 60 and 64 years old in category ACR 4.

The median of the 2-year incidence was $7.5 \%$ in the study population. Increased incidences above this median value were seen in women in breast density categories ACR 3 and ACR 4 except in the youngest age group and in the case of a combination of ACR 2 and the oldest age group. In contrast, a lower 2-year risk was seen for all age groups with density category ACR 1 , for wom- en in the youngest age group regardless of the density category and for ACR 2 except in the oldest age group.

The observations on the singular strongest risk factor for breast cancer "age", the singular risk factor "breast density", and their combination show consistent risk stratifications, published as an absolute 5-year risk for breast cancer [13].

The results of the multicenter approach regarding breast density are in agreement with the previously published results of an individual unit that is integrated in the present evaluation: There is a significant increase in the 2-year incidence from ACR 1 to ACR 3. ACR 4 is comparable to ACR 3 and does not result in a further increase [8]. In the multicenter approach, the program sensitivities differed from those of the published single-center approach for 
- Table 3 Number and 2-year breast cancer incidences of women with screening (ScD)- and interval (ICD)-detected breast cancers (invasive breast cancers plus ductal carcinoma in situ (DCIS)); per 1000 women screened for ACR categories, by age group.

\begin{tabular}{|c|c|c|c|c|c|}
\hline & \multicolumn{4}{|c|}{ 5-year age groups } & \multirow[b]{2}{*}{ p-value ${ }^{1}$} \\
\hline & $50-54$ years & $55-59$ years & $60-64$ years & $65-69$ years & \\
\hline number of women in ACR 1 & 919 & 1829 & 1718 & 2046 & \\
\hline number with $S c D+I C D$ breast cancer & 4 & 3 & 3 & 7 & \\
\hline $\begin{array}{l}\text { 2-year breast cancer incidence } \\
\text { (per } 1000 \text { women screened) }\end{array}$ & 4.4 & 1.6 & 1.7 & 3.4 & \\
\hline adjusted $^{2}$ odds ratio ( $95 \%$ confidence interval) & ref. & $0.37(0.08-1.67)$ & $0.39(0.09-1.77)$ & $0.78(0.23-2.67)$ & 0.45 \\
\hline number of women in ACR 2 & 8766 & 13788 & 12261 & 14533 & \\
\hline number with $S c D+I C D$ breast cancer & 32 & 57 & 69 & 129 & \\
\hline $\begin{array}{l}\text { 2-year breast cancer incidence } \\
\text { (per } 1000 \text { women screened) }\end{array}$ & 3.7 & 4.1 & 5.6 & 8.9 & \\
\hline adjusted $^{2}$ odds ratio ( $95 \%$ confidence interval) & ref. & $1.13(0.73-1.74)$ & $1.53(1.01-2.33)$ & $2.42(1.64-3.57)$ & $<0.001$ \\
\hline number of women in ACR 3 & 12302 & 14829 & 11255 & 11433 & \\
\hline number with SCD+ICD breast cancer & 71 & 139 & 134 & 134 & \\
\hline $\begin{array}{l}\text { 2-year breast cancer incidence } \\
\text { (per } 1000 \text { women screened) }\end{array}$ & 5.8 & 9.4 & 11.9 & 11.7 & \\
\hline adjusted $^{2}$ odds ratio ( $95 \%$ confidence interval) & ref. & $1.63(1.22-2.17)$ & $2.07(1.55-2.76)$ & $2.03(1.52-2.72)$ & $<0.001$ \\
\hline number of women in ACR 4 & 1967 & 1755 & 1126 & 929 & \\
\hline number with $S c D+I C D$ breast cancer & 13 & 17 & 15 & 11 & \\
\hline $\begin{array}{l}\text { 2-year breast cancer incidence } \\
\text { (per } 1000 \text { women screened) }\end{array}$ & 6.6 & 9.7 & 13.3 & 11.8 & \\
\hline adjusted $^{2}$ odds ratio ( $95 \%$ confidence interval) & ref. & $1.43(0.69-2.95)$ & $1.93(0.92-4.08)$ & $1.71(0.76-3.85)$ & 0.35 \\
\hline
\end{tabular}

the less common breast density groups ACR 1 and ACR 4 (ACR 1: $77 \%$ (current study) vs. $100 \%$ [8]; ACR 4: $71 \%$ (current study) vs. $50 \%$ [8]). Given the lower number of cases of cancer, these groups are more susceptible to outliers than ACR 2 and ACR 3 as the main groups. The density groups ACR 1 (5.8\%) and ACR 4 (5.2\%) were seen with a considerably lower prevalence than ACR 2 (44.3\%) and ACR 3 (44.7\%) among 50-69-year-old screening participants in the multicenter approach. The number of cases of cancer (17 (ACR 1) and 56 (ACR 4)) was fundamently less than the number of cases for ACR $2(n=287)$ and ACR $3(n=478)$ so that the results for individual incidences and program sensitivities in the two density groups with low prevalence must be interpreted with caution. At the same time there was no clear association between age and an increase in the 2-year breast cancer incidence in the less common groups (ACR 1 and ACR 4).

While the age of an individual participant is clearly known, the reproducibility of the visual evaluation of BI-RADS density categories by an interpreting physician is considered limited. Automated computer-assisted breast density determination is more consistent than visual evaluation in studies [14, 15] but is not currently established in the clinical routine.
To avoid underestimation, the higher density category was used for analysis in the present study in the case of a discrepancy in ACR category between the first and second independent reading. On average, there was high agreement regarding categorization between the first reading and the second reading. A discrepancy in ACR categorization per examination of $17 \%$ corresponds with the data provided in the literature [16]. There is currently no gold standard regarding the determination of breast density. It is estimated that one in four women can be expected to be assigned to a different density category in the next examination evaluated by the same interpreting physician and one in three women in the case of a different interpreting physician [16]. A change from density category "not dense" (lipomatous, fibroglandular) to "dense" (heterogeneously dense, extremely dense) or vice versa occurs in 13-19\% of women [16]. The interobserver agreement for categorization is described as moderate (kappa: $0.49-0.56$ ) to highly varied (kappa 0.02-0.72) [16]. On the whole, the results of the present study are based on a plausible distribution of the ACR categories without a disproportionate distortion to higher categories compared to published data (ACR 1: 10\%, ACR 2: $40 \%$, ACR 3: $40 \%$, ACR 4: $10 \%$ ) [17]. In the future, analyses of the texture of digital mammograms could provide additional 

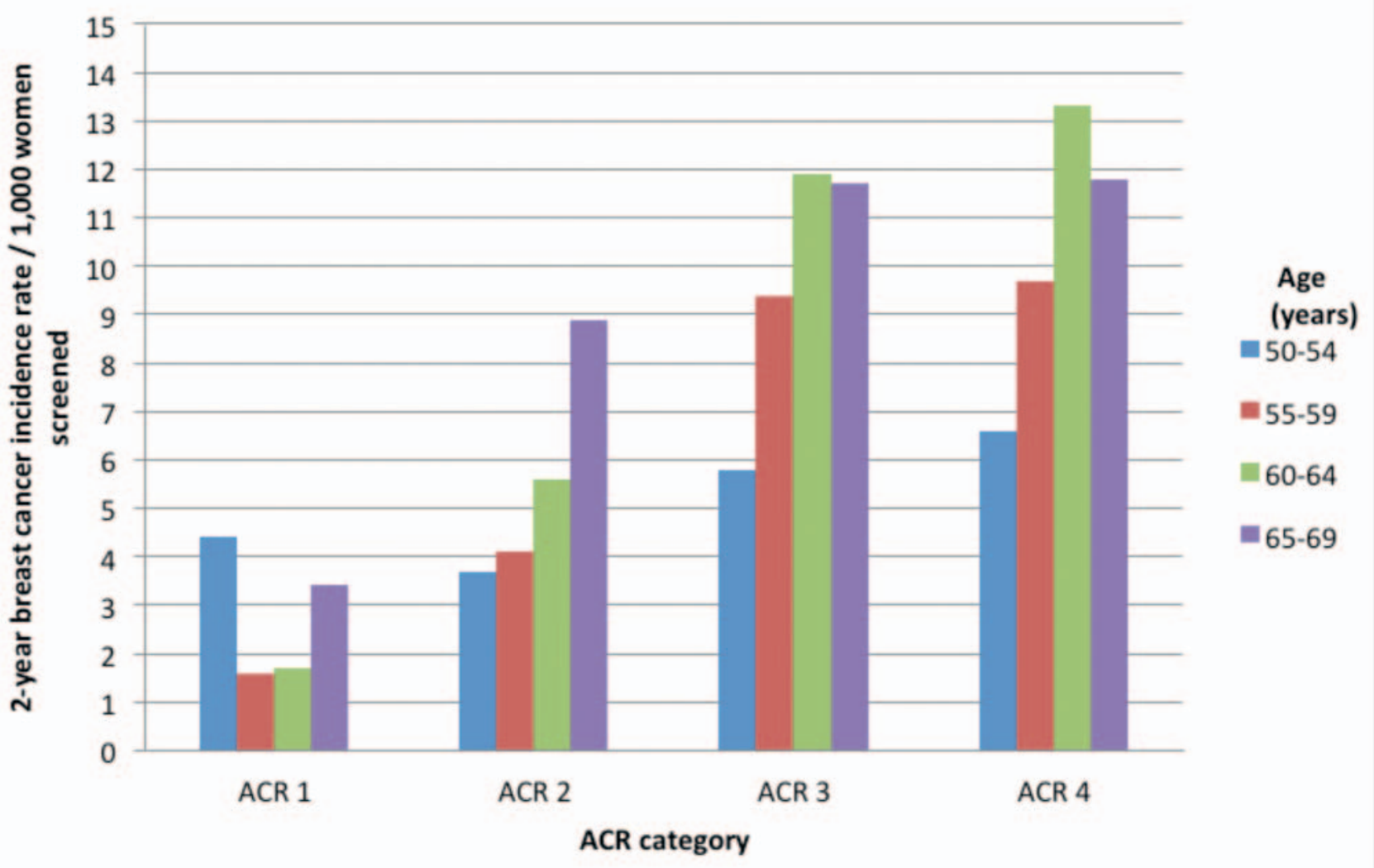

=55-59

$160-64$

65-69

- Fig. 12 -year breast cancer incidence (per 1000 women screened) for screening- plus interval-detected breast cancers (invasive breast cancers plus ductal carcinoma in situ (DCIS)), by ACR category and five-year age group, for women attending subsequent screening rounds.

information for the stratification of breast cancer risk [18]. In principle, analysis of the relationship between the known singular and independent risk factors "age" and "breast density" and the occurrence of breast cancer is of interest [10]. For women older than 50 years in whom a breast cancer-relevant gene mutation has been detected, intensified surveillance including an annual MRI examination is recommended [4]. The significance of MRI for the early detection of a high-risk collective has been shown in a recent study. Among women with the BRCA1 and BRCA2 mutation, $21 \%$ and $36 \%$, respectively, of all cancers diagnosed in the early detection program were detected by MRI [19].

Based on the risk factor "age", women 50 years of age or older, even without a family risk factor, are eligible to participate in early detection imaging in the form of mammography screening every two years in Germany [20]. Decreasing rates of advanced tumor stages among participants in subsequent screening rounds [21] and incidences of aggressive subtypes [22] have been reported. The use of substitute or supplementary methods for dense breasts with the goal of improving cancer detection is discussed in the literature. However, there is no evidence of a reduction in breast cancer mortality for any other imaging examination, such as tomosynthesis, sonography, or MRI [23]. Outside the high-risk situation, sonography is currently the recommended method for supplementing mammography in the dense breast (additional cancer detection 4.4 per 1000). However, in early detection it is associated with a higher rate of additional diagnostic methods and with a low positive predictive value of $3 \%$ to $8.3 \%$ [16]. In the future it would be of interest to identify risk factors for breast cancer or for diagnosis in advanced stages with the goal of modifying risk-adapted screening strategies [14].

A strength of the present scientific analysis is that the selected method allowed combined risk stratification by age and breast density category and that the risk of cancers detected during screening as well as those occurring in the 2-year interval was included. The results are based on a large number of cases using the multicenter approach after program implementation. The results are exclusively from the subsequent screening rounds and are not contaminated by a high percentage of breast cancer cases from initial examinations. The interval cancer data from the screening period 2009 to 2010 were the most current validated data at the time of the evaluation.

A limitation of the study is that the reliability and reproducibility of subjective quantitative breast density determination is limited. Automated validation methods were not available. The aspect of how the diagnosis of breast cancer is distributed in screening and the subsequent interval, which is expressed as the program sensitivity, could not be precisely evaluated for the 16 subgroups resulting from the four 5-year age groups and four ACR categories due to the resulting case number limitations. However, this would be of further interest. As a result of the multi- 


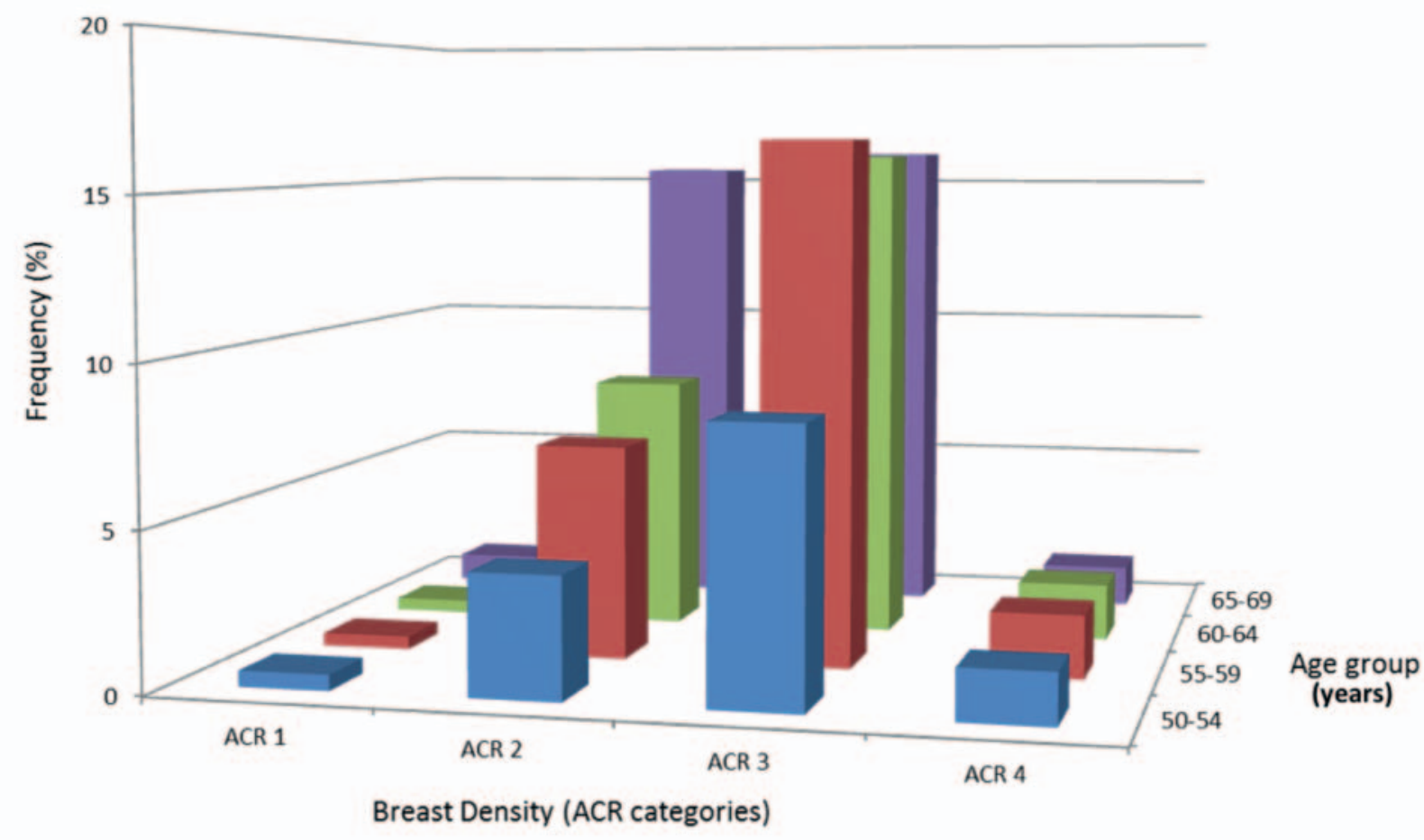

- Fig. 2 Absolute frequency of newly diagnosed breast cancers by screening and during the following interval of two years $(n=838)$ among 111,456 participants of subsequent screening rounds, by breast density category (ACR 1-4) and five-year age group.

center approach and the small number of cases in the less common density categories, the results do not relate to individual screening units.

\section{Conclusion}

In the density categories ACR 2 and ACR 3, the incidences increase significantly up to double as the 5-year age group increases. In contrast, higher breast densities in the youngest age group and higher age in the ACR 1 group do not represent a risk constellation.

\section{CLINICAL RELEVANCE}

- The higher breast cancer incidence associated with breast density is modified by the age of the woman.

- Stratification by age and breast density on mammography identifies constellations for a high or low 2-year breast cancer risk.

- Knowledge of risk constellations is important for early detection concepts.

\section{Conflict of Interest}

The authors declare that they have no conflict of interest.

\section{References}

[1] Robert Koch Institute (ed.) and the Association of Population-based Cancer Registries in Germany (ed.). Cancer in Germany 2011/2012. $10^{\text {th }}$ edition Berlin, 2015

[2] Broeders M, Moss S, Nystrom L et al. The impact of mammographic screening on breast cancer mortality in Europe: a review of observational studies. J Med Screen 2012; 19: 14-25

[3] Lauby-Secretan B, Scoccianti C, Loomis D et al. Breast cancer screeningViewpoint of the IARC working group. N Engl J Med 2015; 373: 2353-2358

[4] Bick U. Intensified surveillance for early detection of breast cancer in high-risk patients. Breast Care 2015; 10: 13-20

[5] www.krebsinformationsdienst.de/tumorarten/brustkrebs/brustkrebsrisi ken-uebersicht.php

[6] Boyd NF, Guo H, Martin LJ et al. Mammographic density and the risk and detection of breast cancer. N Engl J Med 2007; 356: 227-236

[7] Pinsky RW, Helvie MA. Mammographic breast density: effect on imaging and breast cancer risk. J Natl Compr Canc Netw 2010; 8: 1157-1164

[8] Weigel S, Heindel W, Heidrich J et al. Digital mammography screening: sensitivity of the programme dependent on breast density. Eur Radiol 2017; 27: 2744-2751

[9] Checka CM, Chun JE, Schnabel FR et al. The relationship of mammographic density and age: implications for breast cancer screening. Am J Roentgenol 2012; 198: W292-W295

[10] Wengert G], Helbich TH, Kapetas P et al. Density and tailored breast cancer screening: practice and prediction - an overview. Acta Radiol Open 2018; 7: doi:2058460118791212

[11] Anlage 9.2 BMV-Ä/EKV Bundesmantelvertrag Anlage 9.2. Versorgung im Rahmen des Programmes zur Früherkennung von Brustkrebs durch 
Mammografie-Screening. 2014 www.kbv.de/html/bundesmantelver tag.php

[12] American College of Radiology. Breast imaging reporting and data system: BI-RADS atlas. $4^{\text {th }}$ edn Reston: American College of Radiology, VA 2003

[13] Lee Cl, Chen LE, Elmore JG. Risk-based Breast Cancer Screening: Implications of Breast Density. Med Clin North Am 2017; 101: 725-741

[14] Cappello NM, Richetelli D, Lee Cl. The Impact of Breast Density Reporting Laws on Women's Awareness of Density-Associated Risks and Conversations Regarding Supplemental Screening With Providers. J Am Coll Radiol 2019; 16: 139-146

[15] Holland K, van Zelst J, den Heeten G] et al. Consistency of breast density categories in serial screening mammograms: a comparison between automated and human assessment. Breast 2016; 29: 49-54

[16] Melnikow J, Fenton J], Whitlock EP et al. Supplemental Screening for Breast Cancer in Women With Dense Breasts: A Systematic Review for the U.S. Preventive Service Task Force. [Internet]. Rockville (MD): Agency for Healthcare Research and Quality (US) 2016

[17] Sickles EA, D’Orsi C], Bassett LW et al. ACR BI-RADS ${ }^{\circledR}$ Mammography. In: ACR BI-RADS $®$ Atlas, Breast Imaging Reporting and Data System. Reston: American College of Radiology; 2013
[18] Wanders JOP, van Gils $\mathrm{CH}$, Karssemeijer $\mathrm{N}$ et al. The combined effect of mammographic texture and density on breast cancer risk: a cohort study. Breast Cancer Res 2018; 20: 36

[19] Bick U, Engel C, Krug B et al. High-risk breast cancer surveillance with MRI: 10-year experience from the German consortium for hereditary breast and ovarian cancer. Breast Cancer Res Treat 2019; 175: 217-228

[20] Bundesministerium für Umwelt. Naturschutz und nukleare Sicherheit Bekanntmachung der wissenschaftlichen Bewertung des Bundesamtes für Strahlenschutz gemäß § 84 Absatz 3 des Strahlenschutzgesetzes: Brustkrebsfrüherkennung mittels Mammographie vom 16. Dezember 2018. https://www.bundesanzeiger.de

[21] Weigel S, Heindel W, Heidrich J et al. Reduction of Advanced Breast Cancer Stages at Subsequent Participation in Mammography Screening. Fortschr Röntgenstr 2016; 188: 33-37

[22] Prange A, Bokhof B, Polzer P et al. Higher Detection Rates of Biologically Aggressive Breast Cancers in Mammography Screening than in the Biennial Interval. Fortschr Röntgenstr 2019; 191: 130-136

[23] Leitlinienprogramm Onkologie (Deutsche Krebsgesellschaft, Deutsche Krebshilfe, AWMF). S3-Leitlinie Früherkennung, Diagnose, Therapie und Nachsorge des Mammakarzinoms. Version 4.0, 2017 AWMF Registernummer: 032-045OL, http://www.leitlinienprogramm-onkologie.de/ leitlinien/mammakarzinom/ 